\title{
Evaluating the effectiveness of trematocides against Fasciola gigantica and amphistomes infections in cattle, using faecal egg count reduction tests in Iringa Rural and Arumeru Districts, Tanzania
}

\author{
Jahashi Nzalawahe ${ }^{1 *}$, Rose Hannah², Ahmed A. Kassuku², John R. Stothard ${ }^{3}$, Gerald Coles ${ }^{2}$ and Mark C. Eisler ${ }^{2}$
}

\begin{abstract}
Background: Fasciolosis, caused by the liver fluke Fasciola gigantica, and paramphistomosis are widespread in cattle in Tanzania, and the use of trematocides is encouraged by the Government livestock extension officers. However, reduced efficacy of oxyclozanide against Fasciola gigantica and amphistomes (rumen flukes), and albendazole against $F$. gigantica, has been reported in some regions. This study was conducted to assess the efficacy of different trematocides against F. gigantica and amphistome infections in cattle at Iringa Rural and Arumeru Districts.
\end{abstract}

Methods: Cattle found with concurrent infection of F. gigantica and amphistomes were randomly grouped into six experimental groups. One control group was left untreated while five treatment groups were treated with one of five trematocides that include: albendazole, nitroxynil, oxyclozanide, closantel and triclabendazole. Post-treatment faecal sample collection was done on the day of treatment and again at 7, 14 and 28 days, from each cattle. The samples were processed by Flukefinder ${ }^{\oplus}$ method to recover and identify eggs. Assessment of the efficacy of the trematocides against $F$. gigantica and amphistomes was conducted using faecal egg count reduction (FECR) tests.

Results: The findings of the present study in both districts indicate that nitroxynil, oxyclozanide, closantel and triclabendazole are effective against patent $F$. gigantica infection, as the calculated FECR\% for each trematocide was $100 \%$ by day 14 post-treatment. However, albendazole found to have reduced efficacy of against $F$. gigantica, as FECR\% was 49\% in Arumeru District and 89\% in Iringa Rural District by day 14 post-treatment. Oxyclozanide was the only trematocide found to be effective against amphistomes with FECR of 99\%.

Conclusions: Albendazole had reduced efficacy against F. gigantica in cattle in Arumeru and Iringa Rural Districts, Tanzania. The reduced efficacy was prominent in Arumeru, where cattle are commonly treated with anthelmintics, than in Iringa Rural, where cattle are seldom treated.

Keywords: Cattle, Fasciola gigantica, Amphistomes, Trematocide, Efficacy, Tanzania

\footnotetext{
* Correspondence: nzalawahej@gmail.com

${ }^{1}$ Department of Veterinary Microbiology, Parasitology and Biotechnology,

Sokoine University of Agriculture, Morogoro, Tanzania

Full list of author information is available at the end of the article
}

(c) The Author(s). 2018 Open Access This article is distributed under the terms of the Creative Commons Attribution 4.0 International License (http://creativecommons.org/licenses/by/4.0/), which permits unrestricted use, distribution, and reproduction in any medium, provided you give appropriate credit to the original author(s) and the source, provide a link to the Creative Commons license, and indicate if changes were made. The Creative Commons Public Domain Dedication waiver (http://creativecommons.org/publicdomain/zero/1.0/) applies to the data made available in this article, unless otherwise stated. 


\section{Background}

Trematode infections, including fasciolosis and paramphistomosis, are the commonest helminth infections in domesticated ruminants in Tanzania [1]. Fasciolosis, caused by the liver fluke Fasciola gigantica, is widespread in the country $[2,3]$. In contrast, $F$. hepatica appears to be restricted to the Kitulo plateau in southern highlands zone [4]. Recent surveys of cattle in Tanzania observed monthly prevalences of F. gigantica up to $89 \%$ in cattle presented for slaughter in western Tanzania [5] and between-herd prevalences of up to $100 \%$ in some wards [6]. Fasciolosis can incur a significant economic cost at slaughter [7] but the full economic and social impact of subclinical and chronic infections is unknown, and represents a major public health concern. Scanty information is available on the amphistome species responsible for causing paramphistomosis; however, a previous study [8] reported the presence of Calicophoron microbothrium and Cotylophoron jacksoni in Iringa.

Control of trematode infections is mainly achieved through application of trematocides. The commonly used flukicides for treatment of $F$. hepatica infection are albendazole, triclabendazole, nitroxynil, closantel, oxyclozanide, rafoxanide and clorsulon, which have different spectrum of activity against flukes of different ages [9]. The salicylanilides appear effective against both Fasciola spp. and amphistomes and among these oxyclozanide is the recommended drug for the treatment of amphistomes [10-13]. Tanzanian Government livestock extension officers [14] and Community Animal Health Workers [6] recommend the use of trematocide to treat and control trematode infections and improve cattle productivity. However, trematocide resistance has been reported in many countries worldwide [15-19], including Tanzania; reduced efficacy of oxyclozanide against $F$. gigantica and amphistomes, and albendazole against $F$. gigantica, has been reported on an Amani dairy farm in the Kilolo District, Iringa region [20]. This study was designed to determine the efficacy of the commonly used trematocides in Tanzania that include albendazole, nitroxynil and oxyclozanide against Fasciola and amphistome infections in cattle in the Arumeru and Iringa Rural Districts.

\section{Methods}

\section{Study area and cattle management systems}

Cattle involved in this trial were improved dairy breeds (Bos taurus $\times$ B. indicus) in intensive and semi-intensive cattle management systems in the Arumeru District and indigenous breeds ( $B$. indicus) in traditional management systems in the Iringa Rural District [21]. The Arumeru District has three agricultural zones based on the altitude and rainfall that include; coffee-banana (upper zone), middle and lower zones. The coffee-banana zone is characterized by coffee-banana inter-cropping and intensive cattle management systems and has the highest annual rainfall (more than $1200 \mathrm{~mm}$ ). Middle zone has annual rainfall of about $900-1200 \mathrm{~mm}$, with cattle rearing being intensive and semi intensive management systems, whilst the lower zone has the lowest annual rainfall of about $600-800 \mathrm{~mm}$ and cattle's keeping is extensive management system. The study involved the villages from the coffee-banana and middle zones. The livestock farmers in Arumeru District deworm cattle regularly at a range of 2-4 times a year. The Iringa Rural District is an area of high annual rainfall (up to 1600 $\mathrm{mm}$ ) situated in the southern highlands of Tanzania [21]. The study site was located in a village 1600 metres above sea level and is characterized by an extensive floodplain that is inundated with water during the rainy season (December to May) and grazed communally by livestock from the adjacent village the remainder of the year. No treatment records were available for the cattle sampled. However, traditionally managed cattle in the region are very rarely treated for parasites [8]. It is therefore likely that the majority of the cattle in this study have never received anthelmintic treatments.

\section{Experimental design}

The study was conducted in August and September 2013 (Arumeru) and September and October 2014 (Iringa). Five days before beginning the trial in each District, faecal samples were collected from 120 cattle and Fasciola spp. and amphistome eggs enumerated as described below. Cattle were numbered 1-120 using a marking crayon for later identification. Faecal samples were processed using Flukefinder ${ }^{\circledR}$ (Richard Dixon, ID, USA) and recovered eggs were identified and counted using a stereo microscope [1]. Fasciola eggs were distinguished from the amphistome eggs based on their morphological characteristics $[22,23]$. Due to the restricted geographical distribution of F. hepatica in Tanzania, it is likely that the Fasciola eggs observed in this study are of F. gigantica. Sixty animals of all ages (excluding suckling calves) with concurrent infection of $F$. gigantica and amphistomes were selected based on faecal egg count. The selected animals were allocated into six experimental groups of 10 animals each, stratified by faecal egg count to ensure that each group included animals with a range of egg counts. On day 0 (day of treatment) five groups were treated with one of five trematocides purchased in the United Kingdom (Table 1) while a control group was left untreated. Triclabendazole and closantel are not commonly available in Tanzania, but were included for comparative purposes. All animals were ear tagged for identification. In addition, animals were marked with a marking crayon and details of sex and coloration noted in case of loss of ear tags. 
Table 1 Trematocides used in the trial against F. gigantica and amphistome infections in cattle

\begin{tabular}{llll}
\hline Trematocide & Trade name & Dose $(\mathrm{mg} / \mathrm{kg})$ & Administration route \\
\hline Albendazole & Albex 10\% & 7.5 & Oral \\
Nitroxynil & Trodax 34\% & 10 & Subcutaneous \\
Oxyclozanide & Zanil & 10 & Oral \\
Closantel & Flukiver 5\% & 10 & Oral \\
Triclabendazole & Fasinex 240 24\% & 12 & Oral \\
\hline
\end{tabular}

Post-treatment faecal sample collections were done on the day of treatment and again at 7, 14 and 28 days, from each cattle.

\section{Statistical analysis}

Differences in faecal egg counts on day 0 between treatment groups were evaluated using the Kruskal-Wallis test in R [24].

The method for the detection of anthelmintic resistance in nematodes [25] was applied to fluke in this study using the "egg Counts" R package [26]. Effectiveness of a trematocide was determined by calculating the faecal egg count reduction (FECR) and was considered effective when the calculated FECR was $\geq 95 \%$ and $95 \%$ lower confidence limit (LCL) was $\geq 90 \%$ [25]. A limitation of FECR is the variable nature of flukes egg shedding in the host faeces [27] and hence faecal egg counts of day 14 post-treatment were used in FECR calculations as recommended by previous studies [15, 18, 27]. Due to potential variability in the accuracy of the faecal egg counting method for fluke [28], percentages of individuals in each group that were positive for infection on day 14 and/or day 28 post-treatment are also presented, where individuals with $\geq 1 \mathrm{egg} / \mathrm{g}$ were assumed to be infected (positive), and those with 0 eggs/g were assumed to be uninfected [29].

\section{Results}

In Iringa Rural District, two animals from the triclabendazole group were not returned for repeat sampling and were therefore excluded from analysis. Only 8 individuals were allocated to the closantel group and 9 to the control and albendazole groups due to escape of the remaining assigned individuals from the enclosure at the time of treatment (day 0). No animals were lost in Arumeru. Individual faecal egg counts are provided in Tables 2 and 3.

Mean $( \pm \mathrm{SD})$ F. gigantica and amphistomes faecal egg counts for the study animals in Arumeru on day 0 were $16.78 \pm 20.87$ and $64.60 \pm 141.58$, respectively. There were no significant differences in F. gigantica faecal egg counts between treatment groups on day $0\left(\chi^{2}=0.72, d f\right.$ $=5, P=0.98)$. There was a significant difference in amphistomes faecal egg counts between treatment groups $\left(\chi^{2}=13.09, d f=5, P=0.02\right)$, but this was due to three individuals with high faecal egg counts in the control, albendazole and nitroxynil groups.

Mean ( \pm SD) F. gigantica and amphistomes faecal egg counts for the study animals in Iringa on day 0 were $39.43 \pm 58.12$ and $109.61 \pm 147.95$, respectively. There were no significant differences in faecal egg counts between treatment groups on day 0 (F. gigantica: $\chi^{2}=7.15$, $d f=5, P=0.21$; amphistomes: $\chi^{2}=3.90, d f=5, P=0.56$ ).

Nitroxynil, oxyclozanide, closantel and triclabendazole were highly effective against patent $F$. gigantica infections in cattle, reducing faecal egg counts and number of infected animals by $100 \%$, with the exception of one individual in the triclabendazole group in Iringa that produced 2 eggs/g of faeces on day 28 (Tables 3, 4). Reduced efficacy of albendazole was observed in both Iringa and Arumeru Districts and was more pronounced in the Arumeru District (Tables 2, 4). The decrease in faecal egg count in both districts was greater than the decrease in number of infected animals. In Arumeru $90 \%$ of animals treated with albendazole were observed to be positive for F. gigantica infection on day14 and/or 28 despite a 50\% faecal egg count reduction. In Iringa Rural District, $44 \%$ of individuals remained positive, despite a $90 \%$ faecal egg count reduction on day 14 post-treatment (Table 4). Oxyclozanide was the only flukicide found to be effective against patent amphistome infections in cattle (Table 2).

\section{Discussion}

The results of the current work clearly show that nitroxynil, oxyclozanide, closantel and triclabendazole are highly effective against $F$. gigantica in naturally infected Zebu cattle and improved Zebu breeds. These findings concur with previous studies in Tanzania that reported $100 \%$ efficacy of nitroxynil and triclabendazole [20] and 96.7-100\% efficacy of oxyclozanide [30] against F. gigantica in naturally infected cattle. Comparable results based on the faecal egg count reduction test and controlled anthelmintic trials in cattle, sheep and goats have been reported elsewhere in the world [17-19, 31-38]. However, an apparent reduced efficacy of albendazole against $F$. gigantica was observed in this study. Equivalent findings on treatment failure of albendazole to $F$. gigantica have been reported elsewhere in Tanzania [20]. Reduced efficacy of albendazole against $F$. gigantica in the present study can be explained by the widespread use of albendazole in Tanzania for control of nematode infections in domesticated ruminants. Mixed infections of trematodes and gastrointestinal nematodes are very common in cattle, general practices of livestock field officers/farmers in the study areas is mainly to use clinical signs for diagnosis of helminth infections and when albendazole is used to treat suspected nematode infections in cattle adult $F$. gigantica will be exposed to the 
Table 2 Individual egg counts (eggs per gram) and demographic information for cattle treated in the Arumeru District

\begin{tabular}{|c|c|c|c|c|c|c|c|c|c|c|}
\hline \multirow[t]{2}{*}{ Animal ID ${ }^{a}$} & \multirow[t]{2}{*}{ Sex } & \multirow[t]{2}{*}{ Age group } & \multicolumn{4}{|c|}{ Fasciola gigantica } & \multicolumn{4}{|c|}{ Amphistomes } \\
\hline & & & Day 0 & Day 7 & Day 14 & Day 28 & Day 0 & Day 7 & Day 14 & Day 28 \\
\hline $\mathrm{CO1}$ & Female & Adult & 5 & 1 & 2 & 0 & 17 & 11 & 3 & 9 \\
\hline $\mathrm{CO} 2$ & Female & Adult & 12 & 4 & 3 & 6 & 16 & 10 & 6 & 15 \\
\hline $\mathrm{CO} 3$ & Female (pregnant) & Adult & 109 & 4 & 7 & 3 & 726 & 120 & 95 & 40 \\
\hline $\mathrm{CO} 4$ & Female & Adult & 23 & 3 & 9 & 4 & 34 & 11 & 7 & 19 \\
\hline $\mathrm{CO} 5$ & Female & Adult & 18 & 4 & 4 & 2 & 137 & 22 & 57 & 37 \\
\hline $\cos$ & Female & Adult & 8 & 3 & 0 & 0 & 12 & 4 & 2 & 4 \\
\hline $\mathrm{CO} 7$ & Female & Calf & 12 & 2 & 1 & 3 & 71 & 10 & 8 & 30 \\
\hline $\mathrm{CO} 8$ & Female & Adult & 21 & 5 & 5 & 32 & 7 & 2 & 2 & 5 \\
\hline $\operatorname{cog}$ & Female & Adult & 6 & 0 & 0 & 1 & 28 & 16 & 8 & 6 \\
\hline $\mathrm{CO} 10$ & Female & Adult & 4 & 2 & 3 & 1 & 121 & 86 & 79 & 138 \\
\hline AL1 & Female (pregnant) & Adult & 5 & 1 & 2 & 0 & 17 & 11 & 3 & 9 \\
\hline AL2 & Female (pregnant) & Adult & 12 & 4 & 3 & 6 & 16 & 10 & 6 & 15 \\
\hline AL3 & Female & Adult & 109 & 4 & 7 & 3 & 728 & 120 & 95 & 40 \\
\hline AL4 & Female & Adult & 23 & 3 & 9 & 4 & 34 & 11 & 7 & 19 \\
\hline AL5 & Female (pregnant) & Adult & 18 & 4 & 4 & 2 & 137 & 22 & 57 & 37 \\
\hline AL6 & Female & adult & 7 & 3 & 0 & 0 & 12 & 4 & 2 & 4 \\
\hline AL7 & Female & Adult & 12 & 2 & 1 & 3 & 71 & 10 & 8 & 30 \\
\hline AL8 & Female & Calf & 21 & 5 & 5 & 32 & 7 & 2 & 2 & 5 \\
\hline AL9 & Female & Adult & 6 & 0 & 0 & 1 & 28 & 16 & 8 & 6 \\
\hline AL10 & Female & Adult & 3 & 2 & 1 & 1 & 121 & 86 & 79 & 138 \\
\hline TR1 & Female & Calf & 14 & 0 & 0 & 0 & 13 & 10 & 6 & 3 \\
\hline TR2 & Female & Adult & 6 & 0 & 0 & 0 & 55 & 110 & 16 & 65 \\
\hline TR3 & Female & Adult & 7 & 0 & 0 & 0 & 7 & 19 & 20 & 7 \\
\hline TR4 & Female & Adult & 33 & 0 & 0 & 0 & 131 & 93 & 45 & 46 \\
\hline TR5 & Female & Adult & 3 & 0 & 0 & 0 & 9 & 6 & 1 & 1 \\
\hline TR6 & Female & Heifer & 8 & 0 & 0 & 0 & 10 & 5 & 7 & 7 \\
\hline TR7 & Female & Adult & 18 & 0 & 0 & 0 & 4 & 10 & 4 & 6 \\
\hline TR8 & Female (pregnant) & Adult & 6 & 0 & 0 & 0 & 11 & 7 & 2 & 6 \\
\hline TR9 & Female & Adult & 6 & 0 & 0 & 0 & 22 & 37 & 13 & 13 \\
\hline TR10 & Female & Adult & 63 & 0 & 0 & 0 & 6 & 0 & 0 & 3 \\
\hline ZAN1 & Female & Adult & 4 & 0 & 0 & 0 & 267 & 0 & 2 & 11 \\
\hline ZAN2 & Female & Calf & 7 & 0 & 0 & 0 & 4 & 1 & 0 & 0 \\
\hline ZAN3 & Female & Adult & 10 & 0 & 0 & 0 & 4 & 0 & 0 & 0 \\
\hline ZAN4 & Female & Adult & 17 & 0 & 0 & 0 & 72 & 1 & 1 & 0 \\
\hline ZAN5 & Female & Adult & 9 & 0 & 0 & 0 & 92 & 0 & 0 & 0 \\
\hline ZAN6 & Male & Calf & 31 & 0 & 0 & 0 & 45 & 0 & 3 & 7 \\
\hline ZAN7 & Female & Adult & 15 & 0 & 0 & 0 & 11 & 0 & 0 & 0 \\
\hline ZAN8 & Female & Adult & 10 & 0 & 0 & 0 & 8 & 0 & 0 & 0 \\
\hline ZAN9 & Female & Calf & 8 & 0 & 0 & 0 & 2 & 0 & 0 & 0 \\
\hline ZAN10 & Female & Adult & 4 & 1 & 0 & 0 & 22 & 0 & 3 & 0 \\
\hline CL1 & Female & Calf & 11 & 0 & 0 & 0 & 1 & 0 & 0 & 0 \\
\hline $\mathrm{CL} 2$ & Male & Adult & 20 & 0 & 0 & 0 & 1 & 1 & 33 & 4 \\
\hline CL3 & Female & Adult & 7 & 0 & 0 & 0 & 82 & 46 & 0 & 42 \\
\hline
\end{tabular}


Table 2 Individual egg counts (eggs per gram) and demographic information for cattle treated in the Arumeru District (Continued)

\begin{tabular}{|c|c|c|c|c|c|c|c|c|c|c|}
\hline \multirow[t]{2}{*}{ Animal ID ${ }^{a}$} & \multirow[t]{2}{*}{ Sex } & \multirow[t]{2}{*}{ Age group } & \multicolumn{4}{|c|}{ Fasciola gigantica } & \multicolumn{4}{|c|}{ Amphistomes } \\
\hline & & & Day 0 & Day 7 & Day 14 & Day 28 & Day 0 & Day 7 & Day 14 & Day 28 \\
\hline$\overline{C L 4}$ & Female & Adult & 5 & 0 & 0 & 0 & 390 & 427 & 316 & 139 \\
\hline$C L 5$ & Male & Calf & 7 & 0 & 0 & 0 & 5 & 5 & 0 & 3 \\
\hline CL6 & Male & Adult & 44 & 0 & 0 & 0 & 3 & 5 & 1 & 5 \\
\hline $\mathrm{CL} 7$ & Female & Adult & 12 & 0 & 0 & 0 & 4 & 3 & 1 & 0 \\
\hline CL8 & Male & Calf & 16 & 0 & 0 & 0 & 0 & 0 & 0 & 2 \\
\hline CL9 & Female & Adult & 26 & 0 & 0 & 0 & 4 & 0 & 0 & 2 \\
\hline CL10 & Female & Adult & 7 & 0 & 0 & 0 & 17 & 32 & 19 & 21 \\
\hline FAS1 & Female & Adult & 48 & 0 & 0 & 0 & 3 & 1 & 1 & 0 \\
\hline FAS2 & Male & Adult & 12 & 0 & 0 & 0 & 4 & 1 & 1 & 1 \\
\hline FAS3 & Female & Adult & 34 & 0 & 0 & 0 & 153 & 108 & 36 & 53 \\
\hline FAS4 & Female & Calf & 12 & 0 & 0 & 0 & 1 & 0 & 0 & 0 \\
\hline FAS5 & Male & Adult & 14 & 0 & 0 & 0 & 19 & 19 & 11 & - \\
\hline FAS6 & Female & Adult & 5 & 0 & 0 & 0 & 20 & 11 & 12 & 7 \\
\hline FAS7 & Male & Adult & 19 & 0 & 0 & 0 & 7 & 12 & 4 & 4 \\
\hline FAS8 & Male & Weaner & 4 & 0 & 0 & 0 & 3 & 1 & 2 & 0 \\
\hline FAS9 & Female & Adult & 3 & 0 & 0 & 0 & 33 & 65 & 45 & 11 \\
\hline FAS10 & Female & Calf & 3 & 0 & 0 & 0 & 1 & 0 & 0 & 0 \\
\hline
\end{tabular}

${ }^{\mathrm{a}}$ Treatment group is indicated in the ID prefix, where $\mathrm{CO}=$ control, $\mathrm{ALB}=$ Albenil, $\mathrm{TR}=$ Trodax, $\mathrm{ZAN}=\mathrm{Zanil}, \mathrm{CL}=\mathrm{Closantel}(\mathrm{Flukiver})$ and $\mathrm{FAS}=\mathrm{Fasinex}$

lower dose of $7.5 \mathrm{mg} / \mathrm{kg}$, which is recommended for nematodes, instead of $10 \mathrm{mg} / \mathrm{kg}$ as recommended for adult liver flukes. Underdosing is known to be a factor that can lead to selection for resistance in nematodes [5] and this could explain the reduced efficacy of albendazole to Fasciola.

The albendazole FECR of $49 \%$ in the Arumeru District was much lower compared to the Iringa Rural District (89\%), which could be attributed to the routine deworming (2-4 doses per annum) practices in small scale dairy farmers in Arumeru District compared to the traditional livestock farmers in Iringa Rural District that deworm animals when they are clinically sick. However, it is likely that the majority of cattle treated in Iringa had never been exposed to albendazole, and although the impact of historic treatments on the contamination of pasture by resistant fluke cannot be ruled out, it was considered highly unlikely and therefore the reduced efficacy of this drug in Iringa was a surprise.

Albendazole is only effective against adult Fasciola hepatica [9, 33]. Assuming a similar situation in $F$. gigantica, immature fluke present at the time of treatment may have matured within the study period and continued to shed eggs, resulting in the observed treatment failure of albendazole. However the 100\% efficacy of oxyclozanide which is also only effective against adult $F$. hepatica [9] indicates a reduced efficacy of albendazole against $F$. gigantica in these cattle for other reasons than its mode of action.
Cattle were generally in poor body condition and suffered from multiple parasitic infections in addition to liver fluke, including Schistosoma bovis, trichostrongylid nematodes, ticks and mite infestations. It is therefore unlikely that individual weights were underestimated by using the weight tape and therefore under-dosing is unlikely. Cattle were not fasted prior to treatment and evidence of decreased gut transit time (grains in faeces) and subclinical acidosis (sour smelling faeces) was observed in cattle in the Iringa district, which may affect the pharmacokinetics of albendazole [39]. However, if this were the case, then a similar impact on other orally administered trematocides would be expected.

The reduced efficacy of albendazole might be due to features of the Zebu cattle compared with European breeds (e.g. reduced digestive retention times [40] or differences in the pharmacokinetic profile of some drugs [41]). Products containing albendazole are licensed for the control of $F$. hepatica in cattle and therefore the reduced efficacy could also be due to fundamental differences between the susceptibility of $F$. hepatica and $F$. gigantica to the drug.

Oxyclozanide was the only drug found to be effective against amphistomes, in agreement with previously reported findings [12, 13, 42, 43]. However, the observed inefficacy of closantel $(10 \mathrm{mg} / \mathrm{kg})$ against amphistomes in this study is contrary to the findings of Arias et al. [10] in Spain who found closantel to be effective against the amphistome Calicophoron daubneyi. Since the 
Table 3 Individual egg counts (eggs per gram) and demographic information for cattle treated in the Iringa Rural District

\begin{tabular}{|c|c|c|c|c|c|c|c|c|c|c|}
\hline \multirow[t]{2}{*}{$\overline{\text { Animal ID }}{ }^{a}$} & \multirow[t]{2}{*}{ Sex } & \multirow[t]{2}{*}{ Age group } & \multicolumn{4}{|c|}{ Fasciola gigantica } & \multicolumn{4}{|c|}{ Amphistomes } \\
\hline & & & Day 0 & Day 7 & Day 14 & Day 28 & Day 0 & Day 7 & Day 14 & Day 28 \\
\hline $\mathrm{CO} 1$ & Male & Adult & 3 & 8 & 8 & 1 & 18 & 91 & 119 & 311 \\
\hline $\mathrm{CO} 2$ & Female & Adult & 8 & 4 & 0 & 3 & 79 & 24 & 87 & 32 \\
\hline $\mathrm{CO} 3$ & Male & Adult & 21 & 14 & 10 & 19 & 679 & 387 & 395 & 556 \\
\hline $\mathrm{CO} 4$ & Male & Calf & 11 & 6 & 7 & 4 & 260 & 174 & 116 & 479 \\
\hline CO5 & Female & Adult & 49 & 42 & 38 & 105 & 16 & 54 & 48 & 10 \\
\hline CO6 & Male & Adult & 2 & 8 & 16 & 2 & 46 & 111 & 228 & 90 \\
\hline $\mathrm{CO} 7$ & Female & Adult & 62 & 56 & 0 & 12 & 262 & 136 & 140 & 326 \\
\hline $\mathrm{CO} 8$ & Female & Adult & 12 & 64 & 14 & 5 & 21 & 107 & 167 & 92 \\
\hline $\operatorname{cog}$ & Female & Adult & 253 & 97 & 6 & 59 & 16 & 51 & 22 & 8 \\
\hline ALB1 & Male & Adult & 22 & 6 & 0 & 5 & 29 & 13 & 13 & 40 \\
\hline ALB2 & Female & Adult & 16 & 3 & 0 & 0 & 41 & 87 & 74 & 39 \\
\hline ALB3 & Male & Adult & 26 & 3 & 0 & 0 & 375 & 14 & 63 & 177 \\
\hline ALB4 & Male & Adult & 38 & 1 & 8 & 5 & 127 & 67 & 66 & 19 \\
\hline ALB5 & Male & Adult & 12 & 0 & 1 & 0 & 51 & 104 & 171 & 229 \\
\hline ALB6 & Male & Adult & 53 & 0 & 0 & 0 & 244 & 9 & 182 & 298 \\
\hline ALB7 & Male & Calf & 13 & 0 & 1 & 1 & 9 & 2 & 0 & 26 \\
\hline ALB8 & Female & Adult & 37 & 0 & 0 & 0 & 29 & 58 & 149 & 60 \\
\hline ALB10 & Female & Adult & 3 & 0 & 0 & 0 & 97 & 26 & 161 & 235 \\
\hline TR1 & Female & Calf & 3 & 0 & 0 & 0 & 17 & 136 & 159 & 218 \\
\hline TR2 & Male & Adult & 11 & 3 & 0 & 0 & 575 & 13 & 110 & 299 \\
\hline TR3 & Male & Adult & 46 & 0 & 0 & 0 & 0 & 0 & 0 & 0 \\
\hline TR4 & Female & Adult & 28 & 0 & 0 & 0 & 170 & 576 & 987 & 268 \\
\hline TR5 & Female & Adult & 45 & 0 & 0 & 0 & 429 & 336 & 46 & 241 \\
\hline TR6 & Male & Adult & 2 & 0 & 0 & 0 & 39 & 164 & 155 & 377 \\
\hline TR7 & Male & Adult & 10 & 0 & 0 & 0 & 430 & 10 & 151 & 498 \\
\hline TR8 & Female & Adult & 26 & 0 & 0 & 0 & 4 & 52 & 45 & 38 \\
\hline TR9 & Male & Calf & 2 & 0 & 0 & 0 & 6 & 0 & 9 & 50 \\
\hline TR10 & Male & Adult & 21 & 0 & 0 & 0 & 24 & 44 & 23 & 17 \\
\hline ZAN1 & Male & Adult & 7 & 0 & 0 & 0 & 6 & 0 & 0 & 1 \\
\hline ZAN2 & Female & Adult & 144 & 5 & 0 & 0 & 93 & 1 & 0 & 0 \\
\hline ZAN3 & Male & Adult & 24 & 0 & 0 & 0 & 211 & 0 & 0 & 0 \\
\hline ZAN4 & Male & Adult & 28 & 3 & 0 & 0 & 9 & 0 & 0 & 0 \\
\hline ZAN5 & Male & Adult & 112 & 0 & 0 & 0 & 133 & 0 & 0 & 2 \\
\hline ZAN6 & Female & Adult & 33 & 0 & 0 & 0 & 84 & 0 & 0 & 0 \\
\hline ZAN7 & Female & Adult & 94 & 0 & 0 & 0 & 13 & 0 & 5 & 0 \\
\hline ZAN8 & Female & Adult & 48 & 0 & 0 & 0 & 48 & 0 & 0 & 0 \\
\hline ZAN9 & Male & Adult & 18 & 0 & 0 & 0 & 220 & 0 & 11 & 43 \\
\hline ZAN10 & Female & Adult & 253 & 2 & 0 & 0 & 22 & 1 & 0 & 0 \\
\hline CL1 & Female & Adult & 18 & 0 & 0 & 0 & 41 & 28 & 2 & 17 \\
\hline $\mathrm{CL} 2$ & Female & Adult & 21 & 0 & 0 & 0 & 106 & 7 & 92 & 95 \\
\hline CL3 & Female & Adult & 8 & 1 & 0 & 0 & 208 & 477 & 24 & 363 \\
\hline CL4 & Female & Adult & 39 & 3 & 0 & 0 & 53 & 1 & 44 & 19 \\
\hline CL5 & Male & Adult & 2 & 0 & 0 & 0 & 87 & 31 & 6 & 41 \\
\hline
\end{tabular}


Table 3 Individual egg counts (eggs per gram) and demographic information for cattle treated in the Iringa Rural District (Continued)

\begin{tabular}{|c|c|c|c|c|c|c|c|c|c|c|}
\hline \multirow[t]{2}{*}{ Animal ID } & \multirow[t]{2}{*}{ Sex } & \multirow[t]{2}{*}{ Age group } & \multicolumn{4}{|c|}{ Fasciola gigantica } & \multicolumn{4}{|c|}{ Amphistomes } \\
\hline & & & Day 0 & Day 7 & Day 14 & Day 28 & Day 0 & Day 7 & Day 14 & Day 28 \\
\hline$\overline{\mathrm{CL} 6}$ & Female & Adult & 49 & 0 & 0 & 0 & 51 & 9 & 19 & 18 \\
\hline CL7 & Male & Adult & 3 & 0 & 0 & 0 & 131 & 150 & 143 & 106 \\
\hline CL8 & Female & Adult & 16 & 0 & 0 & 0 & 5 & 3 & 0 & 0 \\
\hline FAS1 & Male & Adult & 12 & 0 & 0 & 0 & 2 & 0 & 7 & 4 \\
\hline FAS4 & Female & Adult & 15 & 0 & 0 & 0 & 63 & 46 & 12 & 23 \\
\hline FAS5 & Male & Adult & 241 & 0 & 0 & 2 & 110 & 109 & 157 & 187 \\
\hline FAS6 & Male & Adult & 8 & - & 0 & 0 & 77 & & 234 & 254 \\
\hline FAS7 & & Adult & 27 & 5 & 0 & 0 & 39 & 30 & 18 & 65 \\
\hline FAS8 & Female & Adult & 50 & 1 & 0 & 0 & 10 & 16 & 60 & 8 \\
\hline FAS9 & Male & Adult & 12 & 0 & 0 & 0 & 0 & 7 & 1 & 0 \\
\hline FAS10 & Male & Adult & 12 & 0 & 0 & 0 & 4 & 0 & 5 & 18 \\
\hline
\end{tabular}

${ }^{\mathrm{a}}$ Treatment group is indicated in the ID prefix, where $\mathrm{CO}=$ control, $\mathrm{ALB}=$ Albenil, $\mathrm{TR}=$ Trodax, $\mathrm{ZAN}=\mathrm{Zanil}, \mathrm{CL}=\mathrm{Closantel}(\mathrm{Flukiver})$ and $\mathrm{FAS}=\mathrm{Fasinex}$

current work did not characterize the amphistomes to the species level, the species in the study areas could be other than Calicophoron daubneyi.

Flanagan et al. [27] recommends that efficacy of a trematocide should be determined by FEC of day 14 post-treatment in domesticated ruminants infected with $F$. hepatica, as this sampling time allows the clearance of stored Fasciola eggs from the host gall bladder. However this study has observed that in naturally infected cattle with $F$. gigantica that were treated with the effective trematocides FEC levels fell to negative values within seven days after treatment at Arumeru District, with some cattle having low counts at Iringa Rural District. Similar findings have been observed by Brockwell et al. [15], who reported FEC were reduced to zero by day 7 post-treatment in cattle infected with $F$. hepatica after being treated with the effective trematocide.

\section{Conclusions}

Nitroxynil, oxyclozanide, closantel and triclabendazole were highly effective against patent $F$. gigantica infection in naturally infected cattle. Oxyclozanide was also found to be highly effective against patent paramphistome infection. Treatment failure of albendazole against F. gigantica was observed in both Districts. In the Arumeru District, where albendazole is used regularly to control helminth infections, anthelmintic resistance in $F$. gigantica may contribute to the observed treatment failure, as lower FECR were observed in Arumeru than Iringa Rural. However, in Iringa Rural District, where there is very little history of

Table 4 Efficacies of trematocides to F. gigantica and amphistomes in infected cattle and percentage positive on day 14 and/or day 28 post-treatment

\begin{tabular}{|c|c|c|c|c|c|c|c|}
\hline \multirow[t]{2}{*}{ Trematocide } & \multicolumn{3}{|c|}{ Fasciola gigantica } & \multicolumn{3}{|c|}{ Amphistomes } & \multirow[t]{2}{*}{ District } \\
\hline & FECR (\%) & $95 \%$ LCL & $\%$ positive $(n)$ & FECR (\%) & $95 \%$ LCL & $\%$ positive $(n)$ & \\
\hline \multirow[t]{2}{*}{ Albendazole } & 50 & 0 & $90(9 / 10)$ & 50 & 0 & $100(10 / 10)$ & Arumeru \\
\hline & 90 & 38 & $44(4 / 9)$ & 34 & 0 & $100(9 / 9)$ & Iringa Rural \\
\hline \multirow[t]{2}{*}{ Nitroxynil } & 100 & 100 & $0(0 / 10)$ & 79 & 33 & $100(10 / 10)$ & Arumeru \\
\hline & 100 & 100 & $0(0 / 10)$ & -15 & 0 & $90(1 / 10)$ & Iringa Rural \\
\hline \multirow[t]{2}{*}{ Oxyclozanide } & 100 & 100 & $0(0 / 10)$ & 99 & 95 & $40(4 / 10)$ & Arumeru \\
\hline & 100 & 100 & $0(0 / 10)$ & 99 & 95 & $40(4 / 10)$ & Iringa Rura \\
\hline \multirow[t]{2}{*}{ Closantel } & 100 & 100 & $0(0 / 10)$ & 31 & 0 & $50(5 / 10)$ & Arumeru \\
\hline & 100 & 100 & $0(0 / 8)$ & 72 & 18 & $88(7 / 8)$ & Iringa Rural \\
\hline \multirow[t]{2}{*}{ Triclabendazole } & 100 & 100 & $0(0 / 10)$ & 79 & 25 & $80(8 / 10)$ & Arumeru \\
\hline & 100 & 100 & $13(1 / 8)$ & 58 & 0 & $100(8 / 8)$ & Iringa Rura \\
\hline \multirow[t]{2}{*}{ Control } & na & na & $90(9 / 10)$ & na & na & $100(10 / 10)$ & Arumeru \\
\hline & na & na & $100(9 / 9)$ & na & na & $100(9 / 9)$ & Iringa Rural \\
\hline
\end{tabular}


chemotherapeutic treatment of the cattle, the reason for treatment failure is unknown. However, as a baseline efficacy of albendazole against $F$. gigantica in B. indicus and $B$. indicus $\times B$. taurus has not, to the authors' knowledge, been established, the possibility of reduced efficacy of albendazole against F. gigantica warrants further investigations.

\section{Abbreviations}

$d f$ : Degrees of freedom; FECR: Faecal egg count reduction test; LCL: Lower confidence limit; SD: Standard deviation; $X^{2}$ : Chi-square test

\section{Acknowledgements}

The authors acknowledge the support of local staff within the District Veterinary Office and Veterinary Investigation Centre in Iringa and of farmers in Iringa Rural District during the period of study. Field and technical assistance from Mr L.M.A Kindamba, L.P. Msalilwa, D.S. Mwangoka, R.A. Kassuku, A. Manyesela and Miss J. Longo of Department of Veterinary Microbiology, Parasitology and Biotechnology at Sokoine University of Agriculture. We dedicate this publication to the late Professor Ahmed Ayub Kassuku who devoted his career to the investigation and control of helminth parasites of livestock and zoonotic importance in Tanzania and inspired his students and fellow researchers with his great experience and knowledge.

\section{Funding}

This work was funded by Leverhulme Royal Society, African Award Scheme. The funders had no influence in the design of the study and collection, analysis, and interpretation of data and in writing the manuscript

\section{Availability of data and materials}

All data generated and analyzed in the study are included in this published article.

\section{Authors' contributions}

$J H, A A K, M C E$ and RS designed the study. JH, AAK, MCE, GC and HR performed the experimental work. $\mathrm{JH}$ and $\mathrm{HR}$ analysed the data and prepared the manuscript. All authors read and approved the final manuscript.

\section{Ethics approval and consent to participate}

All work on animals described in this manuscript was conducted in accordance with internationally recognised guidelines and approved by Sokoine University of Agriculture.

\section{Consent for publication}

Not applicable.

\section{Competing interests}

The authors declare that they have no competing interests.

\section{Publisher's Note}

Springer Nature remains neutral with regard to jurisdictional claims in published maps and institutional affiliations.

\section{Author details}

'Department of Veterinary Microbiology, Parasitology and Biotechnology, Sokoine University of Agriculture, Morogoro, Tanzania. ${ }^{2}$ School of Veterinary Sciences, University of Bristol, Langford House, Langford, Bristol BS40 5DU, UK. ${ }^{3}$ Department of Parasitology, Liverpool School of Tropical Medicine, Liverpool, UK.

Received: 17 January 2018 Accepted: 20 June 2018

Published online: 03 July 2018

\section{References}

1. Nzalawahe J, Kassuku AA, Stothard JR, Coles GC, Mark EC. Trematode infections in cattle in Arumeru District, Tanzania are associated with irrigation. Parasit Vectors. 2014;7:107.
2. Forbes $A B$, Reddick D, Stear MJ. Efficacy of treatment of cattle for liver fluke at housing: influence of differences in flukicidal activity against juvenile Fasciola hepatica. Vet Rec. 2015;176:333.

3. Phillips GD, Hungate RE, MacGregor A, Hungate DP. Experiments on rumen retention time, fermentation rate and dry-matter digestibility in zebu and European-type cattle on a grass hay ration. J Agric Sci. 2009;54:417.

4. Islam A. Comparative efficacy of ivermectin plus clorsulon and nitroxynil against naturally infected cattle. Eurasian J Vet Sci. 2013;29:43-5.

5. Mooney L, Good B, Hanrahan JP, Mulcahy G, de Waal T. The comparative efficacy of four anthelmintics against a natural acquired Fasciola hepatica infection in hill sheep flock in the west of Ireland. Vet Parasitol. 2009;164:201-5

6. Rojo-Vázquez FA, Meana A, Valcárcel F, Martínez-Valladares M. Update on trematode infections in sheep. Vet Parasitol. 2012;189:15-38.

7. Rolfe PF, Boray JC. Chemotherapy of paramphistomosis in cattle. Aust Vet J. 1987;64:328-32.

8. Flanagana A, Edgarb H, Gordonc A, Hannab R, Brennana G, Fairweather I. Comparison of two assays, a faecal egg count reduction test (FECRT) and a coproantigen reduction test (CRT), for the diagnosis of resistance to triclabendazole in Fasciola hepatica in sheep. Vet Parasitol. 2011;176:170-176.

9. Novobilsky A, Averpil HB, Hoglund J. The field evaluation of albendazole and triclabendazole efficacy against Fasciola hepatica by coproantigen ELISA in naturally infected sheep. Vet Parasitol. 2012;190:272-6.

10. Nzalawahe J, Komba E. Occurrence and seasonal predisposition of fasciolosis in cattle and goats slaughtered in Kasulu District Abattoir, Western Tanzania. Res Opin Anim Vet Sci. 2013;3:395-400.

11. Roy RM. Oxyclozanide-activity against Fasciola gigantica in naturally infected buffalo, cattle, sheep and goats. Trop Anim Health Prod. 1971;3:26-33.

12. Valero MA, Perez-Crespo IM, Periago V, Khoubbane M, Mas-Coma S. Fluke egg characteristics for the diagnosis of human and animal fascioliasis by Fasciola hepatica and F. gigantica. Acta Trop. 2009;111:150-9.

13. Martínez-Valladares M, Cordero-Pérez C, Rojo-Vázquez FA. Efficacy of an anthelmintic combination in sheep infected with Fasciola hepatica resistant to albendazole and clorsulon. Exp Parasitol. 2014;136:59-62.

14. Gustafson C, VanWormer E, Kazwala R, Makweta A, Paul G, Smith W, et al. Educating pastoralists and extension officers on divers livestock diseases in a changing environment in Tanzania. Pastoralism Res Policy Pract. 2015;5:1.

15. Sanabria R, Ceballos L, Moreno L, Romero J, Lanusse C, Alvarez L. Identification of a field isolate of Fasciola hepatica resistant to albendazole and susceptible to triclabendazole. Vet Parasitol. 2013;193:105-10.

16. Paraud C, Gaudin C, Pors I, Chartier C. Efficacy of oxyclozanide against the rumen fluke Calicophoron daubneyi in experimentally infected goats. Vet J. 2009;180:265-7.

17. Keyyu JD, Monrad J, Kyvsgaard NC, Kassuku AA. Epidemiology of gastrointestinal nematodes in cattle on traditional, small-scale dairy and largescale dairy farms in Iringa District, Tanzania. Vet Parasitol. 2005;127:285-94.

18. Fairweather I, Boray JC. Fasciolicides: efficacy, actions, resistance and its management. Vet J. 1999;158:81-112.

19. Arias MS, Sanchís J, Francisco I, Francisco R, Piñeiro P, Cazapal-Monteiro C, et al. The efficacy of four anthelmintics against Calicophoron daubneyi in naturally infected dairy cattle. Vet Parasitol. 2013:197:126-9.

20. Mahlau EA. Liver fluke survey in zebu cattle of Iringa region, Tanzania and first finding of the small fluke Dicrocoelium hospes Looss. Bull Epizoo Dis Afri. 1970;18:21-8

21. Boulrad C, Carreras F, Van Gool F. Evaluation of nitroxynil and closantel activity using ELISA and egg counts against Fasciola hepatica in experimentally and naturally infected cattle. Vet Res. 1995;26:249-55.

22. Kassuku A, Makundi A, Lekaki K. Efficacy of oxyclozanide and levamisole (Milsan $^{\circledR}$ ) in the treatment of naturally occurring fascioliasis in Iringa. In: Procecedings of 9th Scientific Conference of Tanzania Veterinary Association: AICC Arusha. Morogoro: Tanzania Veterinary Association and Faculty of Veterinary Medicine, Sokoine University of Agriculture. 1991; p. 173-179.

23. Torgerson P, Paul M, Furrer R. Evaluating faecal egg count reduction using a specifically designed package "egg Counts" in R and a user friendly web interface. Int J Parasitol. 2014;44:299-303.

24. Keyyu JD, Kassuku AA, Kyvsgaard NC, Monrad J. Comparative efficacy of anthelmintics against Fasciola gigantica and amphistomes in naturally infected cattle in Kilolo District, Tanzania. Tanzania Vet J. 2008:25:40-7.

25. Keyyu JD, Kassuku AA, Msalilwa LP, Monrad J, Kyvsgaard NC. Cross-sectional prevalence of helminth infections in cattle on traditional, small-scale and largescale dairy farms in Iringa District, Tanzania. Vet Res Commun. 2006;30:45-55. 
26. Gaasenbeek CPH, Moll L, Cornelissen JBWJ, Vellema P, Borgsteede FHM. An experimental study on triclabendazole resistance of Fasciola hepatica in sheep. Vet Parasitol. 2001;95:37-43.

27. Sanchez SF, Alvarez LI, Lanusse CE. Fasting-induced changes to the pharmacokinetic behaviour of albendazole and its metabolites in calves. J Vet Pharm Therap. 1997;20:38-47.

28. Anderson N, Luong T, Vo N, Bui K, Smooker P, Spithill T. The sensitivity and specificity of two methods for detecting Fasciola infections in cattle. Vet Parasitol. 1999;83:15-24.

29. Coles GC, Bauer FHM, Borgsteede S, Geerts S, Klei TR, Taylor MA, et al. WAAVP methods for detection of anthelmintic resistance in nematode of veterinary importance. Vet Parasitol. 1992;44:35-44

30. Walker SM, Makundi AE, Namuba FV, Kassuku AA, Keyyu JD, Hoey EM, et al. The distribution of Fasciola hepatica and Fasciola gigantica within southern Tanzania - constraints associated with the intermediate host. Parasitology. 2008;135:495-503

31. R Core Team. 2014. http://www.r-project.org. Accessed 10 Oct 2015.

32. Galthar CN, Roy M, Roy S. Efficacy of oxyclozanide (Neozide suspension) against paramphistomiasis in buffaloes. Intas Polivet. 2003;4:266-8.

33. Gordon DK, Roberts LC, Lean N, Zadoks RN, Sargison ND, Skuce PJ. Identification of the rumen fluke, Calicophoron daubneyi in GB livestock: possible implications for liver fluke diagnosis. Vet Parasitol. 2013;195:65-71.

34. Shokier KM, Aboelhadid SM, Waleed MA. Efficacy of five anthelmintics against a natural Fasciola species infection in cattle. Beni-Suef Univ J Appl Sci. 2013;2:41-5.

35. Swai E, Mtui P, Mbise A, Kaaya E, Sanka P, Loomu P. Prevalence of gastrointestinal parasite infections in Maasai cattle in Ngorongoro District, Tanzania. Livestock Res Rural Dev. 2006;18:107.

36. Swai E, Ulicky E. An evaluation of the economic losses resulting from condemnation of cattle livers and loss of carcass weight due to fasciolosis: a case study from Hai town abattoir, Kilimanjaro Region, Tanzania. Livestock Res Rural Dev. 2009;21:186.

37. Keyyu JD, Monrad J, Kyvsgaard NC, Kassuku AA. Epidemiology of Fasciola gigantica and amphistomes in cattle on traditional, small scale dairy and large-scale dairy farms in the southern highlands of Tanzania. Trop Anim Health Pro. 2005;37:303-14

38. Coles GC, Rhodes AC, Stafford KA. Activity of closantel against adult triclabendazole resistant Fasciola hepatica. Vet Rec. 2000;146:504.

39. Coles GC, Stafford KA. Activity of oxyclozanide, nitroxynil, clorsulon and albendazole against adult triclabendazole resistant Fasciola hepatica. Vet Rec. 2001;148:723-4.

40. Moll L, Gaasenbeek CPH, Vellema P, Borgsteede FHM. Resistance of Fasciola hepatica against triclabendazole in cattle and sheep in Netherlands. Vet Parasitol. 2000:91:153-8.

41. Murphy TM, Power EP, Sánchez-Miguel C, Casey MJ, Toolan DP, Fagan JG. 42. McKellar Q, Gokbulut C. Pharmacokinetic features of the antiparasitic macrocyclic lactones. Curr Pharm Biotechnol. 2012;13:888-911.

42. McKellar Q, Gokbulut C. Pharmacokinetic features of the antiparasitic macrocyclic lactones. Curr Pharm Biotechnol. 2012;13:888-911.

43. Brockwell YM, Elliott TP, Anderson GR, Stanton R, Spithill TW, Sangster NC Confirmation of Fasciola hepatica resistant to triclabendazole in naturally infected Australian beef and dairy cattle. Int J Parasitol Drugs Drug Resist. 2014:4:48-54.

\section{Ready to submit your research? Choose BMC and benefit from:}

- fast, convenient online submission

- thorough peer review by experienced researchers in your field

- rapid publication on acceptance

- support for research data, including large and complex data types

- gold Open Access which fosters wider collaboration and increased citations

- maximum visibility for your research: over $100 \mathrm{M}$ website views per year

At BMC, research is always in progress.

Learn more biomedcentral.com/submissions 